\title{
Modeling of the Stability of Lead Solid Phases at the WIPP Conditions
}

LUZHENG ZHANG*, LESLIE KIRKES, AND JAY JE-HuN JANG

Sandia National Laboratories ${ }^{1}, 4100$ National Parks

Highway, Carlsbad, NM 88220, USA

(*Corresponding author, E-mail: lnzhan@sandia.gov)

Waste Isolation Pilot Plant, WIPP, is the only actively operational deep geological repository in the world to permanently isolate defense-related transuranic (TRU) nuclear waste. It is located $\sim 2 \mathrm{~km}$ southeast of Carlsbad, New Mexico, U.S.A., built about $660 \mathrm{~m}$ underground in a salt formation. Due to the use of shielded containers for handling and placing the remote-handled waste, the inventory of lead is significantly larger than the actinides in the waste. A great amount of lead will be present in the repository upon closure and contributes to the reduction of actinide's mobility by the competitive formation of complex with, for example, organic ligands over a regulatory period of 10,000 years. Consequently, it is important to predict the solubilities of the expected and experimentally-observed lead phases (e.g., laurionite, blixite) at the WIPP conditions. In this study, the Pitzer thermodynamic model is extended to predict the stability of lead solid phases observed in experiments at those conditions.

Solution chemistry and solid characterization data from our long-term (over 10 year) experiments are used to reevaluate current Pitzer model and interaction parameters at different $\mathrm{pH}$ values and ionic strengths. The Pitzer thermodynamic model with an extensive complexation of dissolved lead is developed and the related-model parameters are derived from these experimental measurements. This presentation will cover the appliation of the extended model to predict the stability of the lead solid phases at varying $\mathrm{pH}$ and ionic strength with and without organic ligands (such as ethylenediaminetetraacetic acid, EDTA).

\footnotetext{
${ }^{1}$ Sandia National Laboratories is a multi-mission laboratory managed and operated by National Technology and Engineering Solutions of Sandia, LLC., a wholly owned subsidiary of Honeywell International, Inc., for the U.S. Department of Energy's National Nuclear Security Administration under contract DE-NA-0003525. This research is funded by WIPP programs administered by the Office of Environmental Management (EM) of the U.S Department of Energy. SAND2020-0803A
} 